\title{
A Case of Adult-Onset Acute Rheumatic Fever With Long-Lasting Atrioventricular Block Requiring Permanent Pacemaker Implantation
}

\author{
Yusuke Oba, ${ }^{1}$ MD, Hiroaki Watanabe, ${ }^{1}$ MD, Yoshioki Nishimura, ${ }^{1}$ MD, Shuichi Ueno, ${ }^{1}$ MD, \\ Takao Nagashima, ${ }^{2} \mathrm{MD}$, Yasushi Imai, ${ }^{1} \mathrm{MD}$, Masahisa Shimpo, ${ }^{1} \mathrm{MD}$, and Kazuomi Kario, ${ }^{1} \mathrm{MD}$
}

\begin{abstract}
SUMMARY
A 45-year-old hypertensive Japanese woman presented with epigastric pain on inspiration, fever, complete atrioventricular block and polyarthritis. Her antistreptolysin O levels were markedly elevated. A diagnosis of rheumatic fever was made according to the modified Jones criteria. She was prescribed loxoprofen sodium, which was partially effective for her extracardiac clinical symptoms. However, she had syncope due to complete atrioventricular block with asystole longer than 10 seconds. Consequently, we implanted a permanent pacemaker. Although we prescribed prednisolone, the efficacy of which was limited for the patient's conduction disturbance, the complete atrioventricular block persisted. In our systematic review of 12 similar cases, the duration of complete heart block was always transient and there was no case requiring a permanent pacemaker. We thus encountered a very rare case of adult-onset acute rheumatic fever with persistent complete atrioventricular block necessitating permanent pacemaker implantation. (Int Heart J 2015; 56: 664-
\end{abstract} 667)

Key words: Carditis, ASO, Complete atrioventricular block

A cute rheumatic fever is an autoimmune disorder following post-suppurative streptococcal pharyngitis, which leads variably to arthritis, chorea, dermal manifestations, and most importantly, carditis. Acute rheumatic fever usually occurs in children between the ages of 5 and 15 years. In Japan and other developed countries, the incidence of acute rheumatic fever has fallen to very low levels due to improved hygienic standards and the routine use of antibiotics for acute pharyngitis. In fact, in Japan, according to a patient survey by the Ministry of Health, Labour and Welfare, it has been too rare a disease to count the total number of patients since 2005.

Cases of adult-onset acute rheumatic fever with complete atrioventricular block have been reported in developed countries, though very rarely. It has been reported that patients with adult-onset acute rheumatic fever sometimes develop complete atrioventricular block due to excessive vagal tonus activation. ${ }^{1)}$ Therefore, most researchers have reported that the dysfunction of the atrioventricular node caused by adult-onset acute rheumatic fever might be transient or reversible. ${ }^{2-7)}$ Against this background, we experienced a very rare case of a patient diagnosed with adult-onset acute rheumatic fever with complete atrioventricular block requiring implantation of a permanent pacemaker. We report the details of this case and discuss the relevant earlier case reports.

\section{Case Report}

Five days before admission, a 45-year-old Japanese woman who had been receiving antihypertensive therapy (doxazosin $1 \mathrm{mg}$ /day) for 3 years presented with epigastric pain on inspiration. She was admitted to another hospital due to fever with temperatures above $38^{\circ} \mathrm{C}$ and complete atrioventricular block ( 65 beats/minute). Neither she nor her family members had any history of upper respiratory tract infection. There was no other history of cardiorespiratory complaints. There was no familial history of any serious diseases.

Physical examination revealed the following; blood pressure $154 / 72 \mathrm{mmHg}$, pulse 55 regular beats per min, and fever $\left(38.4^{\circ} \mathrm{C}\right)$. A cardiovascular examination revealed a Levine II/ VI systolic murmur at the apex.

The initial laboratory examination revealed a white blood cell count of 15,900/ $\mu \mathrm{L}, \mathrm{C}$-reactive protein (CRP) $23.2 \mathrm{mg} / \mathrm{dL}$, brain natriuretic peptide (BNP) $162 \mathrm{pg} / \mathrm{mL}$, and troponin $\mathrm{T}$, negative. Other biochemical parameters were within normal limits. A chest X-ray showed no cardiomegaly. The electrocardiogram analysis revealed complete atrioventricular block with junctional escape rhythm (46 beats/minute) (Figure 1). Echocardiography showed normal findings except for mild mitral regurgitation and cardiac effusion $(8 \mathrm{~mm})$.

She was given cefozopran hydrochloride intravenously at

From the Divisions of ${ }^{1}$ Cardiovascular Medicine and ${ }^{2}$ Rheumatology and Clinical Immunology, Department of Medicine, Jichi Medical University, Tochigi, Japan Address for correspondence: Yusuke Oba, MD, Division of Cardiovascular Medicine, Department of Internal Medicine, Jichi Medical University School of Medicine, 3311-1 Yakushiji, Shimotsuke, Tochigi 329-0498, Japan. E-mail: r0809yo@jichi.ac.jp

Received for publication February 23, 2015. Revised and accepted June 1, 2015.

Released in advance online on J-STAGE November 9, 2015.

All rights reserved by the International Heart Journal Association. 


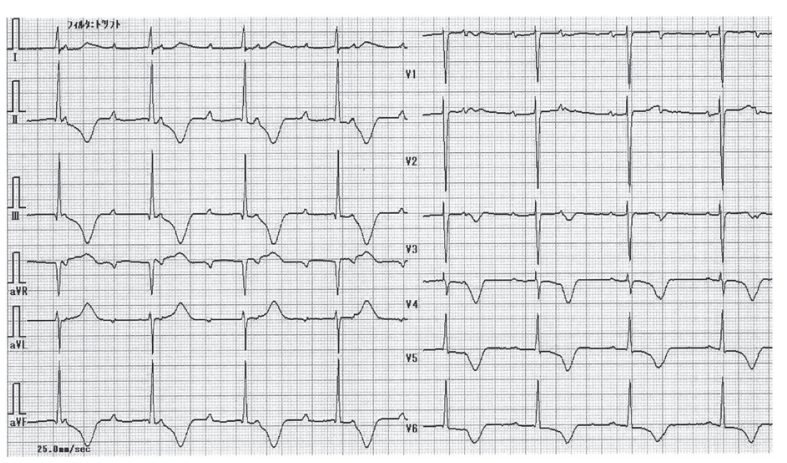

Figure 1. ECG on admission demonstrating complete atrioventricular block.

a dose of $1 \mathrm{~g}$ every 12 hours, but she continued to have fever, epigastric pain on inspiration, and a high level of CRP. Next, we put her on loxoprofen sodium because pericarditis was diagnosed based on the presence of mild cardiac effusion. The day after the initiation of loxoprofen sodium, her temperature and symptoms were alleviated. The CRP level was also markedly improved. The complete atrioventricular block was also intermittently alleviated, but she experienced syncope due to transient complete atrioventricular block with ventricular pause longer than 8 seconds. Therefore, on the 9th hospital day, a temporary pacemaker was inserted.

On the 18th hospital day, we stopped the loxoprofen sodium because the symptoms and inflammation reaction had resolved (CRP $1.2 \mathrm{mg} / \mathrm{dL})$. The next day, the fever and complete atrioventricular block recurred. Moreover, the patient developed polyarthritis involving mainly the left knee, left elbow, and right ankle joints, which was severe enough to limit movement. She was thus transferred to our hospital.

Sarcoidosis was suspected because it is one of the most common diseases that may induce complete atrioventricular block, especially at a young age. However, laboratory examination revealed lysozyme $5.2 \mu \mathrm{g} / \mathrm{mL}(5.0-10.2)$, Ca $8.5 \mathrm{mg} /$ $\mathrm{dL}$, and angiotensin-1-converting enzyme $10.3 \mathrm{mU} / \mathrm{mL}$ (8.321.4). Chest computed tomography showed no bilateral hilar lymphadenopathy or pulmonary lesion. Cardiovascular magnetic resonance imaging showed normal findings. Gallium-67 citrate scintigraphy showed significant uptake only in the left knee. For this reason, sarcoidosis was ruled out in this case.

Systemic autoimmune disease was also suspected because fever, a high level of CRP (16 mg/dL), pericarditis, polyarthritis, and atrioventricular block developed. The test results for rheumatic factors and autoantibodies related to systemic lupus erythematosus and antineutrophil cytoplasmic antibody (ANCA)-associated vasculitis diseases were negative. Antistreptolysin O (ASO) and antistreptokinase (ASK) levels were particularly elevated (ASO $2420 \mathrm{U} / \mathrm{mL}$ [< 160], ASK 5120 times $[<1280]$ ). Although the patient had no history of upper respiratory tract infection, it was clear that she had a history of hemolytic streptococcus infection. A diagnosis of rheumatic fever was made according to the modified Jones criteria.

We restarted the administration of loxoprofen sodium. In addition, we put her on amoxicillin (AMPC) $750 \mathrm{mg}$ to prevent a secondary hemolytic streptococcus infection. On the

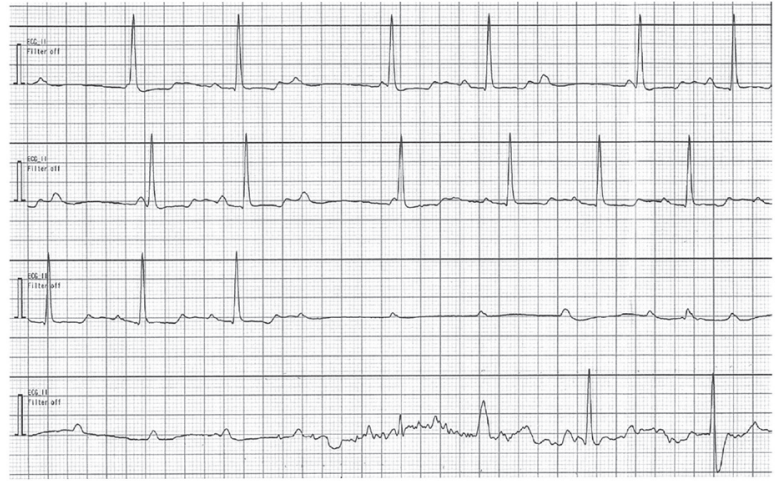

Figure 2. ECG demonstrating 2nd-degree or advanced atrioventricular block in the former half but spontaneous transition to complete atrioventricular block without escape beats.

39th hospital day, we removed the temporary pacemaker because we were afraid of a blood stream infection and stable junctional rhythm (HR 50-60/minute) was maintained. However, she experienced syncope due to transient complete atrioventricular block with ventricular pause longer than 10 seconds (Figure 2). On the 49th hospital day, because she was afebrile and her CRP level was as low as $2.5 \mathrm{mg} / \mathrm{dL}$, a dual chamber permanent pacemaker was implanted. The loxoprofen sodium treatment was continued. The inflammatory reaction improved but did not become negative (CRP $2.5 \mathrm{mg} / \mathrm{dL}$ ). On the 60th hospital day, we decided to start prednisolone (PSL) $60 \mathrm{mg} /$ day. She was also prescribed aspirin instead of loxoprofen sodium because aspirin is the generally recommended drug for acute rheumatic fever. On the 64th hospital day, the level of CRP was improved $(0.2 \mathrm{mg} / \mathrm{dL})$. We decreased the dosage of PSL by 10 mg every 2 weeks (Figure 3 ). At 5 months after the onset of acute rheumatic fever, almost all of the ventricular beats were fusion comprising intrinsic atrioventricular conduction and pacing and when we changed to a longer atrioventricular delay $(250 \mathrm{msec})$, ventricular pacing was inhibited. At 12 months after the onset, the percentage of ventricular pacing was kept as low as $22 \%$. However, the percentage of ventricular pacing was finally increased and at 20 months after the onset, she became dependent on ventricular pacing and pacemaker check-up showed complete atrioventricular block.

At 26 months post-onset, we decided to restart PSL at 50 $\mathrm{mg}$ /day. However, the conduction disturbance did not improve. Because the patient exhibited side effects such as weight gain, glucose tolerance disorder, and hypertension, we did not continue the PSL (Figure 4). We have not observed any other signs suggesting valvular disease during the 3 years of follow-up. Systematic review: We examined the English and Japanese literature to review other cases of complete atrioventricular block due to adult-onset rheumatic fever. We performed a systematic survey of the Pub-Med database (years 1950-2014) and the Japan Medical Abstracts Society database (years 1983-2014) using the key words "block" and "rheumatic fever." We found 7 cases with complete atrioventricular block due to adult-onset rheumatic fever in Japan and 5 such cases in other developed countries (Table). ${ }^{2-7)}$ We defined adults as over 15 years old.

The patients were aged 16 to 40 years: teens, 3 cases (25\%); 20's, 3 cases (25\%); 30's, 5 cases (41.7\%); 40's, 1 case 


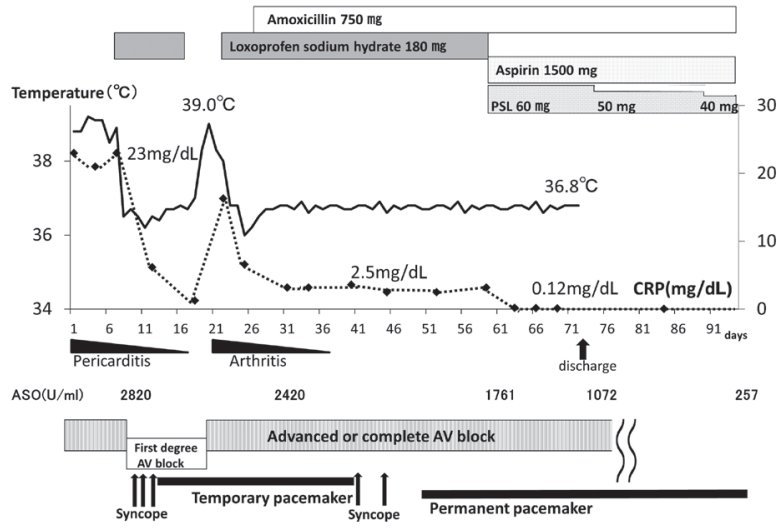

Figure 3. Time course of the present case in acute phase. ASO indicates anti-streptolysin $\mathrm{O}$ antibody; CRP, C-reactive protein; AV block, atrioventricular block; and PSL, prednisolone.

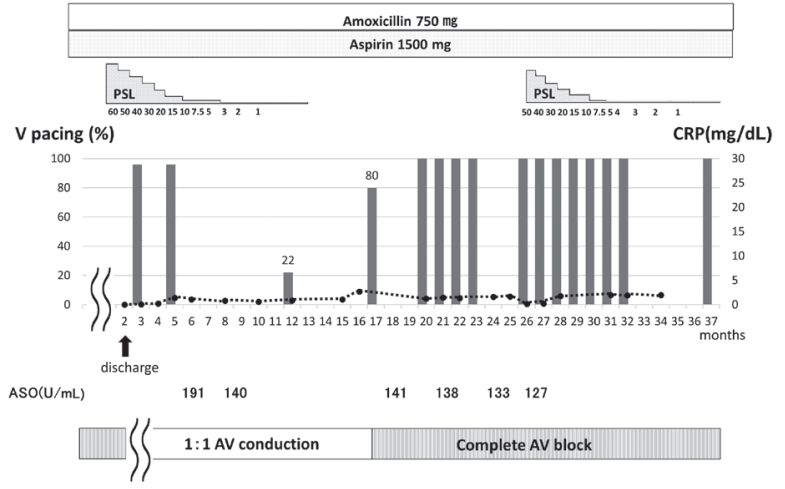

Figure 4. Time course of the present case in chronic phase. $V$ pacing indicates ventricular pacing.

Table. Systematic Review of Cases With Atrioventricular Block due to Rheumatic Fever

\begin{tabular}{|c|c|c|c|c|c|c|c|c|c|}
\hline Case & $\begin{array}{c}\text { Age } \\
\text { (years) }\end{array}$ & Gender & $\begin{array}{l}\text { Duration of complete } \\
\text { AV block }\end{array}$ & Outcome* & temporar & $\begin{array}{l}\text { cing } \\
\text { permanent }\end{array}$ & Treatment & ASO titer & CRP \\
\hline $\begin{array}{l}\text { Baracchi }^{1)} \\
\text { (Italian) }\end{array}$ & 33 & Male & 4 days & $\begin{array}{l}\text { Normal PR } \\
\text { (15 days) }\end{array}$ & $(-)$ & $(-)$ & PSL & 500 Todd unit & $2+$ \\
\hline $\begin{array}{l}\text { Takada } \\
\text { (Japanese) }\end{array}$ & 27 & Male & 2 days & $\begin{array}{c}\mathrm{I}^{\circ} \mathrm{AV} \text { block } \\
<2 \text { months follow-up }>\end{array}$ & $(-)$ & $(-)$ & PSL & 333 Todd unit & $6+$ \\
\hline $\begin{array}{c}\mathrm{Ide}^{2)} \\
\text { (Japanese) }\end{array}$ & 40 & Male & Not described & $\begin{array}{l}\text { Normal PR } \\
\text { (18 days) }\end{array}$ & $(+)$ & $(-)$ & PSL & 250 Todd unit & $5+$ \\
\hline $\begin{array}{c}\text { Tampieri }^{3)} \\
\text { (Italian) }\end{array}$ & 37 & Male & 2 days & $\begin{array}{l}\text { Normal PR } \\
\text { (15 days) }\end{array}$ & $(+)$ & $(-)$ & NSAIDs, PSL & Not described & Not described \\
\hline $\begin{array}{c}\text { Endo } \\
\text { (Japanese) }\end{array}$ & 34 & Male & 1 day & $\begin{array}{l}\text { Normal PR } \\
\text { (18 days) }\end{array}$ & \multicolumn{2}{|c|}{ Not described } & Not described & 320 Todd unit & $6+$ \\
\hline $\begin{array}{l}\text { Iwakuni } \\
\text { (Japanese) }\end{array}$ & 17 & Male & Not described & $\begin{array}{l}\text { Normal PR } \\
\text { (21 days) }\end{array}$ & $(-)$ & $(-)$ & PSL & 320 Todd unit & most positive \\
\hline $\begin{array}{l}\text { Honda } \\
\text { (Japanese) }\end{array}$ & 22 & Male & 1 day & $\begin{array}{l}\text { Normal PR } \\
\text { (1 day) }\end{array}$ & $(-)$ & $(-)$ & NSAIDs & $321 \mathrm{IU} / \mathrm{mL}$ & $18.3 \mathrm{mg} / \mathrm{dL}$ \\
\hline $\begin{array}{l}\text { Yoshikata } \\
\text { (Japanese) }\end{array}$ & 38 & Male & 3 days & $\begin{array}{l}\text { Normal PR } \\
\text { (17 days) }\end{array}$ & $(+)$ & $(-)$ & PSL & $463 \mathrm{IU} / \mathrm{mL}$ & $7 \mathrm{mg} / \mathrm{dL}$ \\
\hline $\begin{array}{l}\text { Ichiki } \\
\text { (Japanese) }\end{array}$ & 22 & Male & 2 days & $\begin{array}{l}\text { Normal PR } \\
\text { (8 days) }\end{array}$ & $(-)$ & $(-)$ & NSAIDs & $926 \mathrm{IU} / \mathrm{mL}$ & $19.9 \mathrm{mg} / \mathrm{dL}$ \\
\hline $\begin{array}{l}\text { Malik }^{4)} \\
\text { (Indian) }\end{array}$ & 16 & Male & A few minutes & $\begin{array}{c}\text { Normal PR } \\
\text { (A few minutes) }\end{array}$ & $(-)$ & $(-)$ & NSAIDs & $310 \mathrm{IU} / \mathrm{mL}$ & Not described \\
\hline $\begin{array}{l}\text { Mohindra } \\
\text { (Indian) }\end{array}$ & 38 & Male & 5 days & $\begin{array}{l}\text { Normal PR } \\
\text { (10 days) }\end{array}$ & $(+)$ & $(-)$ & Not described & 405 Todd unit & + \\
\hline $\begin{array}{l}\text { Duran }^{6} \\
\text { (Turk) }\end{array}$ & 17 & Female & 1 day & $\begin{array}{l}\text { Normal PR } \\
\text { (5 days) }\end{array}$ & $(+)$ & $(-)$ & NSAIDs & 870 Todd unit & $13.2 \mathrm{mg} / \mathrm{dL}$ \\
\hline $\begin{array}{l}\text { Our case } \\
\text { (Japanese) }\end{array}$ & 45 & Female & continued & Complete AV block & $(+)$ & $(+)$ & NSAIDs, PSL & $2420 \mathrm{U} / \mathrm{mL}$ & $23.2 \mathrm{mg} / \mathrm{dL}$ \\
\hline
\end{tabular}

"The parenthesis ( ) indicates duration until PR time was normalized.

(8.3\%). Eleven of these 12 patients were male. The duration of complete atrioventricular block varied from a few minutes to 5 days. The duration of a prolonged PR interval on the electrocardiogram ranged from several minutes to 2 months. Although temporary pacemaker implantation was necessary in 5 cases $(41.7 \%)$, no case required a permanent pacemaker.
Five cases were treated with PSL (41.7\%), 4 with nonsteroidal anti-inflammatory drugs $(33.3 \%)$, and one with a combination of PSL and nonsteroidal anti-inflammatory drugs $(8.3 \%)$. In two cases, the treatment was unknown (16.7\%). The duration of complete atrioventricular block did not differ significantly according to treatment. In 11 of the 12 cases, an ele- 
vated ASO level was reported. In the rest of the cases, the ASO level was not reported.

\section{Discussion}

In the present case, a middle-aged female was clearly diagnosed with rheumatic fever with complete atrioventricular block presenting with an Adams-Stokes attack according to the modified Jones criteria. In our systematic review of similar cases, the duration of complete heart block was always transient (less than 5 days), and there was no case requiring a permanent pacemaker. However, our patient required permanent pacemaker implantation on the 49th hospital day due to prolonged complete atrioventricular block.

It is unknown how acute rheumatic fever leads to impairment in the cardiac conduction system. According to one report, the reason for the conduction disturbance may be increased vagal tone. ${ }^{1)}$ Among the 12 cases collected in our systematic review, the duration of complete atrioventricular block ranged from several minutes to 5 days, and a permanent pacemaker was only required in our case. In the present case, even though we continued to administer loxoprofen sodium, the inflammatory reaction did not improve, and the complete atrioventricular block was also prolonged. When we put our patient on PSL for the first time, she transiently recovered 1:1 atrioventricular conduction and her inflammatory reaction became negative. The course of her case suggests that complete atrioventricular block in rheumatic fever is at least partially caused by inflammation of the conduction system.

In this patient's case, it took a long time to recognize that the conduction disturbance was caused by rheumatic fever because she did not have a typical history of rheumatic fever such as an upper respiratory tract infection or polyarthritis. Sarcoidosis was suspected for the first time because it is one of the most common diseases that may induce complete atrioventricular block, especially at a young age. Interventricular thinning is the most specific characteristic feature of cardiac sarcoidosis in echocardiograms, whereas interventricular septal thickening is also reported. ${ }^{8)}$ In our case, interventricular septal thickening was normal and we have not observed any other signs suggesting sarcoidosis during the 3 years of follow-up. Furthermore, we should also rule out systemic autoimmune disease such as systemic lupus erythematosus and ANCA-associated vasculitis diseases. ${ }^{9)}$ However, systemic autoimmune diseases were ruled out in this case. After her polyarthritis developed, we measured her ASO level. Generally, ASO is elevated in $75 \%$ of acute rheumatic fever cases, ${ }^{10)}$ and thus can be useful to promptly diagnose and treat rheumatic fever. Indeed, in our systematic review, the ASO level was elevated in all of the cases in which the data were available (Table).

In our systematic review, we found no relationship between the ASO level and the duration of complete atrioventricular block. However, our patient had a remarkably higher ASO level than any of these previous cases. This might indicate that she also had a higher autoimmune response and level of inflammatory activity than any of the other cases. In turn, this could have been one of the reasons for the conduction disturbance, because of the secondary cardiac inflammation including atrioventricular node and the His bundle.
Although there were no significant sex differences in acute rheumatic fever including children (males 53\%, females $47 \%$ ) by World Health Organization (WHO) region and for all reported studies, ${ }^{10)}$ there has been no report about sex differences in adult onset rheumatic fever. In our systematic review, there were only two female patients including our case. In addition, our patient was older than the patients in our systematic review. Female sex and age might be associated with complications such as atrioventricular block after acute rheumatic fever. However, to clarify the prognostic factors of rheumatic fever, we must survey more cases in the future.

Conclusions: Although extremely rare, cases of adult-onset rheumatic fever with complete atrioventricular block have been reported. The present patient's case led us to consider that adult-onset rheumatic fever may be one of the causes of complete atrioventricular block with undetermined etiology. Because our patient did not exhibit typical symptoms of adult-onset rheumatic fever, it was important to measure her ASO level to make a differential diagnosis of this disease. A permanent pacemaker might be necessary in cases of adult-onset acute rheumatic fever with persistent atrioventricular conduction disturbance.

\section{Disclosure}

Conflict of interest: The authors state that they have no conflicts of interest to report.

\section{REFERENCES}

1. Keith JD. Over-stimulation of the vagus nerve in rheumatic fever. Q J Med 1938; 7: 29-42.

2. Baracchi G. On 2 cases of complete atrioventricular block (acute and reversible) caused by rheumatic myocarditis. Minerva Med 1963; 54: 2952-60. (Italian)

3. Ide N, Akamatsu T, Otomi S, Ito T, Ohta S. An adult case of suspected rheumatic fever accompanied with Adams-Stokes attacks and a variety of arrhythmia (author's transl). Kokyu To Junkan 1977; 25: 823-31. (Japanese)

4. Tampieri E, Berdondini RM, Leonardi G, Mantovani R. Complete atrioventricular block caused by rheumatic myocarditis and complicated by a Morgagni-Adam-Stokes attack in an adult hyperthyroid patient. Discussion of a clinical case and review of the literature. Minerva Cardioangiol 1984; 32: 421-6. (Italian)

5. Malik JA, Hassan C, Khan GQ. Transient complete heart block complicating acute rheumatic fever. Indian Heart J 2002; 54: 91-2.

6. Mohindra R, Pannu HS, Mohan B, et al. Syncope in a middle aged male due to acute rheumatic fever. Indian Heart J 2004; 56 : 668-9.

7. Duran NE, Sönmez K, Bieteker M, Ozkan M. A case of acute rheumatic fever presenting with syncope due to complete atrioventricular block. Anadolu Kardiyol Derg 2009; 9: 68-9.

8. Nureki S, Miyazaki E, Nishio S, et al. Interventricular septal thickening as an early manifestation of cardiac sarcoidosis. Int Heart J 2014; 55: 181-3.

9. Hara T, Yamaguchi $\mathrm{K}$, Iwase $\mathrm{T}$, et al. Eosinophilic myocarditis due to Churg-Strauss syndrome with markedly elevated eosinophil cationic protein. Int Heart J 2013; 54: 51-3.

10. Seckeler M, Hoke TR. The worldwide epidemiology of acute rheumatic fever and rheumatic heart disease. Clin Epidemiol 2011; 22: 67-84. 